\title{
PENGARUH HEADING GAME TERHADAP KETEPATAN HEADING SEPAK BOLA DI CLUB GASTRA KABUPATEN KAYONG UTARA
}

\author{
Andika Triansyah $^{1}$, Burhanudin ${ }^{2}$, Mimi Haetami ${ }^{3}$ \\ Program Studi Pendidikan Jasmani FKIP Untan Pontianak \\ andika.triansyah@fkip.untan.ac.id
}

\begin{abstract}
ABSTRAK
Penelitian ini bertujuan untuk mengetahui apakah terdapat pengaruh heading game terhadap ketepatan heading sepak bola. Penelitian ini dilakukan di club Gastra Kabupaten Kayong Utara. Metode penelitian yang digunakan adalah eksperimen dengan design one grup pretest and posttest. Pengambilan sampel dengan menggunakan teknik total sampling yaitu seluruh atlet diclub Gastra Kabupaten Kayong Utara yang berjumlah 20 orang. Analisis data yang digunakan pada penelitian ini yaitu Uji-t, tetapi sebelum uji-t terlebih dahulu dilakukan uji normalitas dan uji homogenitas. Hasil dari penelitian adalah adanya pengaruh heading game terhadap ketepatan heading sepak bola berdasarkan perolehan nilai $t_{\text {hitung }}>t_{\text {tabel }}$ yaitu sebesar 17,80>1,7291, dengan perbedaan rata-rata pada saat pretest 25,6 dan nilai rata-rata saat posttest sebesar $46,65 . \mathrm{Ha}=$ diterima dan $\mathrm{Ho}=\mathrm{di}$ tolak. Berarti terdapat pengaruh heading game terhadap ketepatan heading sepak bola
\end{abstract}

Kata Kunci : Heading Game, Ketepatan Heading.

\section{THE EFFECT OF HEADING GAMES ON THE ACCURACY OF SOCCER HEADINGS IN CLUB GASTRA, KAYONG UTARA DISTRICT}

\begin{abstract}
ABSTRAK
This study aims to determine whether there is an effect of the heading game on the accuracy of soccer headings. This study aims to determine whether there is an effect of heading game on the accuracy of soccer headings. This research was conducted at the Gastra club, Kayong Utara Regency. The research method used was experimental design with one group pretest and posttest. Sampling using a total sampling technique, namely all athletes in the Gastra club, Kayong Utara Regency, totaling 20 people. The data analysis used in this study was the t-test, but before the ttest, the normality and homogeneity tests were first carried out. The result of the research is the influence of the heading game on the accuracy of soccer headings based on the acquisition of tcount> ttable, which is 17.80>1.7291, with an average difference of 25.6 at pretest and an average value at posttest of 46, 65. Ha = accepted and Ho = rejected. This means that there is an effect of the game heading on the accuracy of the soccer headings.
\end{abstract}

Keywords: Heading Game, Heading Accuracy

Dipublikasikan Oleh :

UPT Publikasi dan Pengelolaan Jurnal

Universitas Islam Kalimantan Muhammad Arsyad Al-Banjari Banjarmasin 


\section{PENDAHULUAN}

Dalam usaha meningkatkan mutu permainan sepak bola kearah prestasi maka masalah penguasaan teknik dasar merupakan salah satu syarat yang sangat menentukan. Menurut Nugraha (2012:10) "sepak bola adalah olahraga yang memainkan bola dengan menggunakan kaki, tujuan utamanya dari permainan ini adalah untuk mencetak gol atau skor sebanyak-banyaknya yang tentunya harus dilakukan sesuai dengan ketentuan yang telah ditetapkan, untuk bisa membuat gol kalian harus tangkas, sigap, cepat, dan baik dalam mengontrol bola." Dari beberapa teknik dasar sepak bola antara lain. Menendang, menghentikan bola, mengiring bola, heading (menyundul bola) dan shooting bola. Dari berbagi teknik diatas heading bola merupakan teknik dasar dan penting dalam permainan sepak bola. Pemain sepak bola harus mahir dalam heading bola dengan berbagai cara. Dengan heading bola pemain dapat menciptakan gol kegawang lawan saat menyerang dan sebaliknya bertahan, kemampuan heading bola sangat diperlukan saat menghalau serangan lawan melalui udara maupun umpan-umpan pendek.

Heading pada hakekatnya memainkan bola menggunakan kepala. kegunaan heading Menurut Effendi. dkk (2017:5) "kegunaan heading (menyundul bola) yaitu meneruskan bola atau mengoperkan bola kepada teman operan jarak pendek, memasukan bola ke mulut gawang lawan (membuat gol), menyapu bola didaerah pertahanan sendiri untuk mematahkan serangan lawan (mempertahankan gawang sendiri)." Menurut Maslikhah (2013:519) "menyudul bola merupakan salah satu teknik dasar yang harus dikuasai oleh pemain sepak bola pada umumnya bola yang di sundul adalah bola di atas yang melambung tinggi Ditinjau dari posisi tubuhnya, heading dapat dilakukan sambil berdiri, melompat, dan sambil meloncat."Sedangkan Menurut Atiq dkk (2019:24)" heading adalah salah satu teknik dasar yang terdapat dalam permainan sepak bola. Teknik ini merupakan salah satu cara dalam sepak bola untuk mengumpan atau mencetak gol" Kenyataan terjadi saat ini di club pemain sepak bola di kabupaten kayong utara kurangnya kemampuan dalam melakukan heading dan juga lemah saat melakukan heading hingga sundulannya tidak jauh bahkan ada atlet saat melakukan heading dengan mata tertutup karna takut hingga sasaran melakukan sundulan tidak tepat. Hal ini menunjukan pada saat atlet menyundul bola kurang rileks, salah satu penyebab atlet karena kurangnya latihan dan juga kurangnya mengerti tentang teknik melakukan heading yang baik dan bener. Adapun latihan yang di berikan adalah berbasis game atau permainan heading untuk meningkatkan ketepatan heading agar sasaran yang diinginkan tercapai dan tepat. Unsur ketepatan juga sangat berperan penting dalam melakukan heading disamping unsur-unsur yang lainnya. Unsur ketepatan atau akurasi perlu dilatih karena sangat dibutuhkan dalam mencapai keterampilan yang optimal.

Menurut Widiastuti (2015:17) "ketepatan sebagai keterampilan motorik merupakan komponen kesegaran jasmani yang diperlukan dalam kegiatan anak sehari-hari, ketepatan dapat berupa gerakan (performance) atau sebagai ketepatan hasil (result)." Sedangkan Menurut Nurrochmah (2016:186) "ketepatan adalah kemampuan tubuh untuk menempatkan/meletakan suatu benda dengan efektif, efesien sesuai dengan kehendak dan mengurangi kesalahan sekecil mungkin kemampuan tubuh untuk mengendalikan gerak-gerak bebas menuju kesasaran.”

Adapun faktor-faktor yang mempengaruhi ketepatan. Menurut Anam (2013:80) yaitu "faktor internal dan faktor eksternal. faktor internal yaitu faktor-faktor yang berasal dari dalam diri subjek sehingga dapat dikontrol oleh subjek itu sendiri, seperti koordinasi, ketajaman indera, penguasaan teknik, cepat lambatnya gerak, ball feeling, dan ketelitian serta kuat atau lemahnya suatu gerakan. faktor eksternal yaitu faktor yang dari luar subjek, seperti besar kecilnya sasaran dan jauh dekatnya sasaran". Dalam permainan ini digunakan untuk persiapan memperoleh kemampuan kematangan bertanding Permainan ini lebih menekankan unsur kesenangan agar dalam melaksanakan dalam kemampuan heading atlet lebih santai dan tidak takut dalam melakukan heading, adapun permainan yang diberikan antara lain,: bermain heading berpasangan, bermain heading berpasangan dengan rintangan tali, bermain heading mengenai bola kegawang, bermain heading dengan zig-zag, bermain heading mengenakan bola 4 penjuru, bermain heading 
mengenakan bola kebawah, bermain heading bola depan belakang, bermain juggling heading , bermain heading estafet, bermain heading dengan memasukan bola kegawang.

Menurut Atiq (2014:28) "bermain membawa seseorang mengalami perubahan fisiologi yang lebih baik, dimana tekanan yang dialami akibat aktivitasnya, seseorang yang melakukan aktivitas bermain dapat memiliki suasana hati yang senang, gembira dan rileks. sedangkan Menurut Rizki (2017:3) "bermain merupakan suatu kegiatan yang sangat disenangi dan digemari seseorang tanpa adanya paksaan tekanan untuk melakukan suatu aktivitas belajar sehingga dapat memberikan ekspresi terhadap pemikiran dan menjadi lebih kreatif." Artinya bahwa bermain atau permainan adalah suatu kegiatan yang sama-sama memiliki menimbulkan kesenangan untuk melepaskan energi yang dilakukan secara suka rela tanpa paksaan dan rasa tanggung jawab dan tanpa mempertimbangkan hasil akhir yang berfungsi sebagai pengembangan potensi dan kreatifitas anak.

Ada juga Faktor-faktor latihan Menurut Budiwanto (2012:32-33) "fakto-faktor latihan meliputi persiapan fisik, teknik dan fsikis (mental).“ Faktor-faktor latihan tersebut saling berhubungan dan disusun dalam program latihan dan merupakan bagian penting dari setiap program latihan, meskipun faktor-faktor saling berkaitan erat tetapi masing-masing mempunyai cara dalam mengembangkan persiapan fisik dan teknik memberikan dasa pembentukan kemampuan berikutnya. Kemampuan fisik diperlukan untuk memperoleh keterampilan teknik yang lebih baik dipersiapkan untuk memperoleh maka bermanfaat selain faktor yang di terapkan ada prinsip -prinsip latihan menurut Hadisasmita dan syarifuddin (dalam reval 2013:5) bahwa prinsip-prinsip latihan meliputi: (a) Prinsip beban latihan; (b) Prinsip intensitas latihan; (c) Prinsip kualitas latihan; (d) Prinsip variasi dalam latihan.

\section{METODE PENELITIAN}

Penelitian ini menggunakan bentuk penelitian eksperimen dengan desain bentuk One Group Pretest and Posttest. Menurut Soekidjo Notoatmodjo (2012: 57) rancangan ini juga tidak ada kelompok pembanding (kontrol), tetapi paling tidak sudah dilakukan observasi pertama (pretest) yang memungkinkan menguji perubahan-perubahan yang terjadi setelah adanya eksperimen (program). Sehingga rangkaian dalam desain penelitian ini yaitu terdapat tes awal atau yang disebut pretest untuk mengetahui kemampuan atlet dalam melakukan heading, kemudian diberikan perlakuaan (treatment) yaitu dengan memberikan latihan berbasis game atau permainan heading desain ini di gambarkan sebagai berikut:

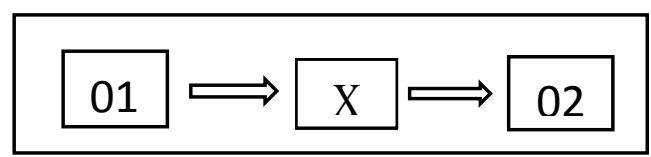

Gambar 1. Prosedur Penelitian

Sumber : (Soekidjo Notoatmodjo 2012:57)

Keterangan.

01:pretest

02:posttest

$\mathrm{X}$ : treatment / pelakuan

Populasi dalam penelitian ini adalah pemain Sepak Bola, di club Gastra Kabupaten Kayong Utara yang berjumlah 20 orang. Sampel dalam penelitian ini menggunakan metode total sampling artinya semua pemain di club kabupaten kayong utara yang berjumlah 20 orang.

Menurut Sugiyono (2018:102) insterumen penelitian adalah suatu alat yang digunakan mengukur fenomena alam maupun sosial yang diamati. Adapun Teknik pengumpulan data merupakan langkah yang paling strategis dalam penelitian, karena tujuan utama dari penelitian adalah mendapatkan data. Kesimpulan diatas artinya teknik pengumpulan data yang digunakan adalah dengan teknik tes dengan pengukuran tes keterampilan heading

\section{HASIL PENELITIAN DAN PEMBAHASAN \\ Hasil Penelitian}

Dalam penelitian ini yang dijadikan sampel adalah seluruh di club Gastra di kabupaten kayong utara yang berjumlah 20 orang. Adapun tujuan dari penelitian ini adalah untuk mengetahui apakah terdapat pengaruh heading game terhadap ketepatan heading sepak bola. Deskripsi Data Dipublikasikan Oleh : 
Penelitian Berikut ini adalah hasil pengolahan data yang telah dilakukan dari hasil penelitian baik tes awal (pretest) maupun tes akhir (posttes).

Tabel 1: Deskripsi Data Pretest Dan Posttest

Adapun deskripsi data penelitian di atas berdasarkan tabel menunjukan hasil kemampuan atlet yang terdiri dari 20 sampel maka diperoleh hasil pretest untuk rata-rata 25,6 skor terendah 10, skor tertinggi 50 dengan standar deviasi 9,00, dan hasil posttest untuk rata-rata 46,65, skor terendah 30, skor tertinggi 70, dengan standar deviasi 11,46. Adapun grafik diagram hasil rata-rata pretest dan posttest dapat digambarkan sebagai berikut.

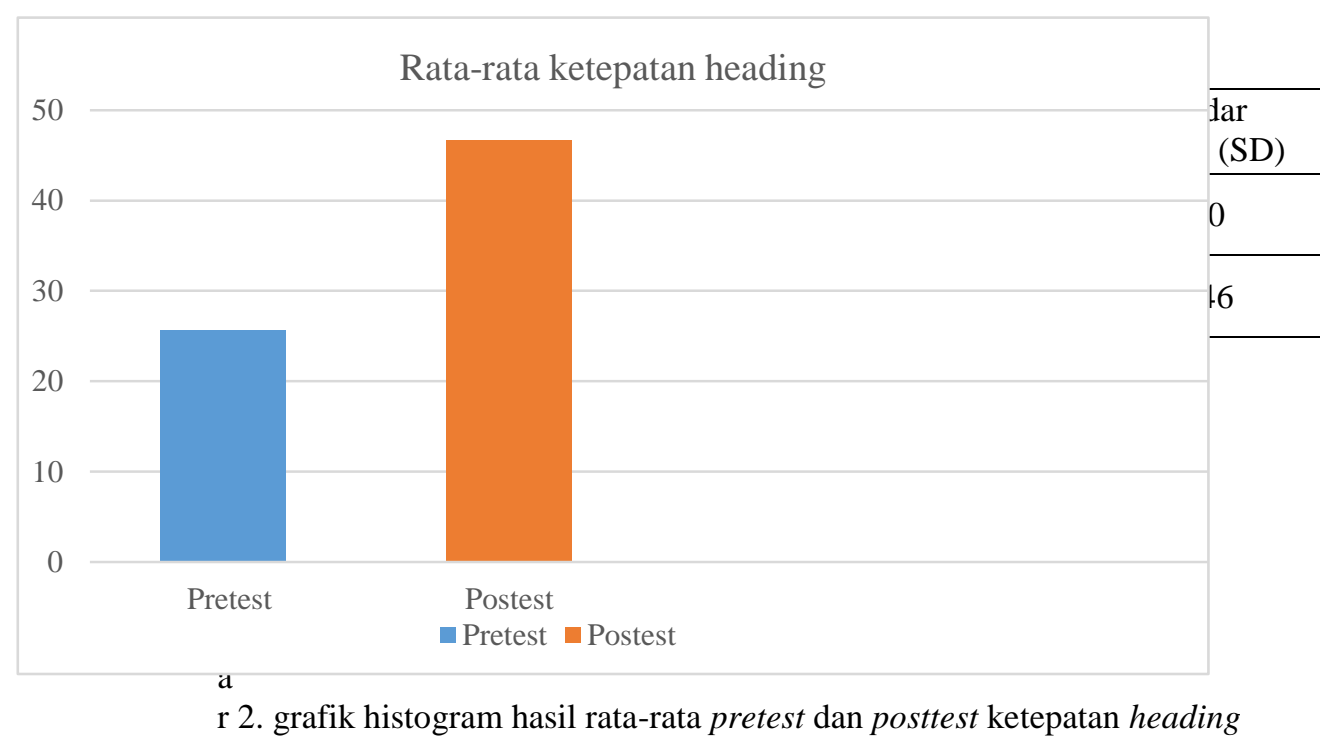

Analisis data digunakan untuk menjawab hipotesis yang telah diajukan. Uji analisis yaitu uji normalitas, uji homegenitas dan uji hipotesis menggunakan uji t. Hasil uji normalitas dan uji t dapat dilihat sebagai berikut:

a) Uji Normalitas

Perhitungan normalitas bertujuan untuk mengetahui apakah sampel berasal dari populasi yang berdistribusi normal. Kriteria jika chi-kuadrat hitung<chi-kuadrat tabel maka sebaran berdistribusi normal, dan sebaliknya apabila jika chi-kuadrat hitung>chi-kuadrat tabel maka sebaran berdistribusi tidak normal. Hasil uji normalitas penelitian ini dapat dilihat pada tabel berikut. Hasil pada tabel diatas, diketahui data kemampuan ketepatan heading pretest di peroleh nilai $\mathrm{x} 2$ hitung $(7,69)<\mathrm{x} 2$ tabel $(7,815)$ jadi dapat di simpulkan data ketepatan heading pretest berdistribusi normal. Data ketepatan heading posttest di peroleh nilai x2 hitung $(7,09)<\mathrm{x} 2$ tabel ( 7,815 ). Jadi dapat disimpulkan data ketepatan heading posttest berdistribusi normal. Hasil uji normalitas dapat dilihat pada lampiran sebagai berikut

Tabel 2 . Hasil uji normalitas

\begin{tabular}{ccccccc}
\hline Tes & $\mathbf{N}$ & $\mathbf{d k}$ & Mean & $\mathbf{X}^{2}$ hitung & $\mathbf{X}^{2}$ tabel 5\% & ket \\
\hline Pretest & 20 & 3 & 25,6 & 7,69 & 7,815 & Normal \\
\hline Posttest & 20 & 3 & 46,65 & 7,09 & 7,815 & \multirow{2}{*}{ Normal } \\
\hline
\end{tabular}


b) Uji Homogenitas

Uji homogenitas berguna untuk menguji kesamaan sampel yaitu seragam atau tidak varian sampel yang diambil dari populasi. Kriteria homogenitas jika $\mathrm{F}_{\text {hitung }}<\mathrm{F}_{\text {tabel }}$ test dinyatakan homogen, jika $\mathrm{F}_{\text {hitung }}>\mathrm{F}_{\text {tabel }}$ test dikatakan tidak homogen. Hasil uji homogenitas penelitian ini dapat dilihat pada tabel beriku

Tabel 3. Hasil Uji Homogenitas

\begin{tabular}{|c|c|c|c|c|c|}
\hline keterangan & $\mathbf{N}$ & Varians & $\mathbf{F}_{\text {hitung }}$ & $\mathbf{F}_{\text {tabel }}$ & Ket \\
\hline Pretest & 20 & 11,42 & & & \\
\hline posttest & 20 & 12,60 & 1,10 & 4,45 & homogen \\
\hline
\end{tabular}

erdasarkan tabel di atas, hasil perhitungan uji homogenitas data hasil pretest dan posttest di peroleh $F_{\text {hitung }}=1,10$, sedangkan $F_{\text {tabel }}=4,45$. Dari hasil perhitungan uji homogenitas tersebut didapatkan $\mathrm{F}_{\text {hitung }}<\mathrm{F}_{\text {tabel }}$, maka dapat disimpulkan bahwa data hasil pretest dan posttest hasil ketepatan heading dikatakan sama atau homogen

c) Uji Hipotesis ( Uji-t )

Pengujian hipotesis dilakukan untuk mengetahui penerimaan atau penolakan hipotesis yang diajukan. Uji hipotesis menggunakan uji- t pada taraf signifikan 5\% hasil uji hipotesis ( uji-t ) dapat dilihat pada tabel dibawah ini

$\begin{array}{lllll}\text { Tabel } & 4 & \text { Hasil } & \text { Uji } & -t\end{array}$

\begin{tabular}{lccccc}
\hline \multicolumn{1}{c}{ Tes } & Rata-rata & $\mathbf{t}_{\text {hitung }}$ & d.b & $\mathbf{t}_{\text {tabel }}$ & $\begin{array}{c}\text { Taraf } \\
\text { Signifikan }\end{array}$ \\
\hline pretest & 25,6 & 17,80 & 19 & 1,7291 & $5 \%$ \\
\hline Posttest & 46,65 & & & & \\
\hline
\end{tabular}

Berdasarkan tabel di atas maka dapat dinilai $t_{\text {hitung }}$ yaitu sebesar 17,80 dengan melihat tabel statistika dimana pada drajat kebebasan $\mathrm{dk}=(\mathrm{N}-1)$ adalah $20-1=19$ dan pada taraf signifikan 5\% (uji dua sisi ) diperoleh nilai $t_{\text {tabel }} 1,729$. Dengan demikian nilai dari $\mathrm{T}_{\text {hitung }}=17,80$ lebih besar dari nilai $\mathrm{t}_{\text {tabel }}=1,729$ arti nya hipotesis diterima bearti dapat disimpulkan terdapat pengaruh melalui heading game terhadap ketepatan heading sepak bola di club Gastra Kabupaten Kayong Utara untuk melihat peningkatan ketepatan heading diperoleh melalui $\frac{\text { Mean Deviasi }}{\text { Mean pretest }} \times 100 \%$, mean deviasi pada data 21 sedangkan mean pretest 26 sehingga diperoleh pengaruh sebesar 80,76\%

\section{HASIL DAN PEMBAHASAN}

Pada penelitian ini merupakan penelitian eskperiment untuk meningkatkan ketepatan heading seorang atlet yaitu melalui permainan heading atau heading game dalam sepak bola dengan menggunakan program latihan yang dilakukan atlet diclub Gastra Kabupaten Kayong Utara. Tujuan dari latihan yang berbasis game agar atlet lebih rileks, senang dan atlet tidak merasakan tertekan saat melakukan sundulan

Menurut Nugroho (2017: 100) bermain merupakan aktivitas jasmani yang dilakukan dengan sukarela dan bersungguh-sungguh untuk memperoleh rasa senang dari melakukan aktivitas tersebut. Artinya atlet melakukan heading tanpa ada rasa paksaan dan melakukannya dengan sungguhsungguh, bertanggung jawab, dan rasa senang tanpa mempertimbangkan hasil akhir.Adapun faktor yang mempengaruhi ketepatan seorang atlet Menurut Harmono (2014: 53) yaitu penguasaan teknik, ball feeling, jauh dekatnya sasaran, cepat lambatnya gerakan dalam melakukan heading, besar kecilnya sasaran, koordinasi tinggi bearti ketepatan baik. Sedangkan Menurut Nurrochmah (2016: 186)"ketepatan adalah kemampuan tubuh untuk menempatkan/meletakan suatu benda dengan efektif, 
efesien sesuai dengan kehendak dan mengurangi kesalahan sekecil mungkin kemampuan tubuh untuk mengendalikan gerak-gerak bebas menuju kesasaran."

Pada penelitian dilakukan dengan melihat ketepatan heading atlet melalui test awal (pretest), pelakukan (treatment) dan tes akhir (posttest) dengan program latihan 12 kali pertemuan Setelah proses penelitian dilakukan maka tahapan selanjutnya yaitu menganalisis uji pengaruh antar tes awal dan tes akhir, dimana berdasarkan hasil analisis data penelitian maka dapat dinyatakan bahwa pada tes awal diperoleh nilai kemampuan yang lebih rendah dibandingkan tes akhir. Berdasarkan hasil penelitian dan anlisis uji pengaruh yang telah dilakukan maka dapat disimpulkan bahwa terdapat pengaruh heading game terhadap ketepatan heading sepak bola diclub Gastra Kabupaten Kayong Utara yang signifikan. Hasil rata-rata atlet pada pretest adalah 25,6 sedangkan rata-rata posttest adalah 46,65 dengan presentase peningkatan ketepatan heading 80,76\% .Berdasarkan hasil pengolahan data melalui analisis statistik dapat dilihat bahwa setelah membandingkan antara tes awal dan tes akhir sebagian besar hasil yang diperoleh atlet mengalami peningkatan. Hal ini tentunya tidak lepas dari pengaruh variasi-variasi latihan yang telah dibuat berbentuk pemainan heading.

Dapat disimpulkan dari penelitian dan teori-teori diatas bahwa berbasis game atau permainan dapat mempengaruhi ketepatan heading sepak bola pada dasarnya atlet lebih senang melakukan latihan berbasis permainan ketimbang melakukan latihan fisik karna permainan atlet lebih rileks, senang, sungguh-sungguh tanpa ada paksaan dan atlet juga mempunyai kebebasan dalam melakukan gerakan tanpa ada tekanan sesuai latihan yang di terapkan. Namun ada beberapa hal yang menjadi kendala dalam penelitian yaitu cuaca,lapangan, dan waktu karna menyesuaikan jadwal sekolah dan saat penelitian dikarena rata-rata atlet masih seorang pelajar. Meskipun demikian peneliti dan pelatih melatih sekaligus memberikan perlakuan terhadap atlet dapat mengatasi masalah-masalah tersebut, sehingga peneliti dapat berjalan dengan lancar.

\section{PENUTUP}

Kesimpulan

Berdsasarkan analisis data dapat dilihat thitung > ttabel atau hasil thitung sebesar 17,80 dan ttabel 1,7291 artinya hipotesis diterima maka dapat ditarik kesimpulan yaitu terdapat pengaruh secara signifikan heading game terhadap ketepatan heading sepak bola dapat dilihat nilai rata-rata pretest 25,6 sedangkan posttest 46,65 dengan menggunakan sampel sebanyak 20 orang dengan persentase peningkatan $80,76 \%$. Ada beberapa saran yang dapat peneliti kemukakan, antara lain:

1. Penerapan metode permainan diharapkan sebagai acuan untuk atlet lebih berpartisipasi dalam kegiatan latihan agar menjadi lebih bermanfaat.

2. Pelatih diharapkan bisa menerapkan latihan bervariasi berbentuk game dalam proses latihan atau dengan memodifikasi latihan atlet lebih senang dan bersemangat.

3. Pada pihak club memberi dukungan atau motivasi dan juga menambah sarana dan prasarana agar atlet lebih aktif dalam mengikuti latihan.

\section{REFERENSI}

Atiq. A, Dkk (2019) Sepak Bola Untuk Pemula pola latihan Menyerang Dan Bertahan , Bekasi: Penerbit Cakrawala Cendekia

Atiq, A. (2014). Model latihan teknik dasar sepak bola berbasis bermain. Sidoarjo: Zifatma Jawar

Anam Khoiril (2013) pengembangan latihan ketepatan tendangan dalam sepak bola untuk anak kelompok umur 13-14 tahun. Retrieved 2020, from jurnal media ilmu keolahragaan indonesia Volume 3 Nomor 2 http://journal.unnes.ac.id/nju/index.php/miki

Budiwanto,S.(2012) Metodelogi Latihan Olahraga. Malang.Universitas Negeri Malang

Effendi Yusuf (2017) Pengaruh Latihan Jump Heading Untuk Meningkatkan Keterampilan Heading Pada Tim Sekolah Sepak Bola Bina Bakat U-15 Pekan Baru. Retrieved februari 2020, from jurnal Online Mahasiswa Fakultas Keguruan Dan Ilmu Pendidikan Universitas Riau Volume 4 Nomor 1 Https://Www.Neliti.Com/Publications/209299/

Maslikhah \& Gatot, D. (2013). Upaya Peningkatan Hasil Belajar Heading Ball Dalam Permainan Sepak Bola Dengan Modifikasi Bola Plastik. Retrieved November 2019, from jurnal ilmiah Volume 01 Nomor 03 https://jurnalmahasiswa.unesa.ac.id

Dipublikasikan Oleh :

UPT Publikasi dan Pengelolaan Jurnal

Universitas Islam Kalimantan Muhammad Arsyad Al-Banjari Banjarmasin 
Notoatmodjo Soekidjo. (2012). Metodologi Penelitian Kesehatan. Jakarta: PT. Rineka Cipta

Nugraha, A. (2012). Mahir Sepak bola. Bandung: Nuansa Cendekia

Nurrochmah, Siti (2016). Tes dan pengukuran dalam pendidikan jasmani \& keolahragaan. Malang:Universitas Negeri Malang .

Harmono, Bayu, Akbar. (2014). Kontribusi Konsentrasi Terhadap Ketepatan Pukulan Jumping Smash Pada Bulutangkis Studi pada Atlet Putra Usia 16-20 Tahun PB. Citra Raya Unesa Surabaya.

Jurn, Volume 2, No 1, 2014 .https://jurnalmahasiswa.unesa.ac.id/index.php/jurnal-kesehatan olahraga/article/view/6402

Prasetyo Rizki (2017) Pengaruh Metode Bermain Terhadap Hasil Belajar Heading Sepak Bola Pada Peserta Didik SMP. Retrivied Februari 2020, From jurnal pendidikan dan pembelajaran $\begin{array}{llll}\text { khatulistiwa } & \text { Volume } & \text { Nomor }\end{array}$ http://jurnal.untan.ac.id/index.php/jpdpb/article/view/19911

Reval (2013) Pengaruh Latihan Back Up Terhadap Kemampuan Heading Dalam Permainan Sepak Bola Pada Siswa Mts Al Khairaat Pinotu Kabupaten Parigi Moutong. Retrived januari 2020, from jurnal olahraga Volume 1 Nomor 3: https://docplayer.info/32505678

Susanto Nugroho (2017) hakikat dan signifikansi permainan. Retrieved juni 2020, from jurnal jendela olahraga Volume 2 Nomor 1 http://journal.upgris.ac.id/

Sugiyono (2018) Metode Penelitian Kualitatif kuantitatif dan R\&D. Bandung: Alfabeta

Widiastuti. (2015). Tes Dan Pengukuran Olahraga. Jakarta:Rajawali Pers. 